\title{
Hepatic IGFBP1 is a prosurvival factor that binds to BAK, protects the liver from apoptosis, and antagonizes the proapoptotic actions of p53 at mitochondria
}

\author{
J. I-Ju Leu and Donna L. George ${ }^{1}$ \\ Department of Genetics, University of Pennsylvania School of Medicine, Philadelphia, Pennsylvania 19104, USA
}

\begin{abstract}
Liver is generally refractory to apoptosis induced by the p53 tumor suppressor protein, but the molecular basis remains poorly understood. Here we show that p53 transcriptional activation leads to enhanced expression of hepatic IGFBP1 (insulin-like growth factor-binding protein-1). Exhibiting a previously unanticipated role, a portion of intracellular IGFBP1 protein localizes to mitochondria where it binds to the proapoptotic protein BAK and hinders BAK activation and apoptosis induction. Interestingly, in many cells and tissues p53 also has a direct apoptotic function at mitochondria that includes BAK binding and activation. When IGFBP1 is in a complex with BAK, formation of a proapoptotic p53/BAK complex and apoptosis induction are impaired, both in cultured cells and in liver. In contrast, livers of IGFBP1-deficient mice exhibit spontaneous apoptosis that is accompanied by $\mathrm{p} 53$ mitochondrial accumulation and evidence of BAK oligomerization. These data support the importance of BAK as a mediator of p53's mitochondrial function. The results also identify IGFBP1 as a negative regulator of the BAK-dependent pathway of apoptosis, whose expression integrates the transcriptional and mitochondrial functions of the p53 tumor suppressor protein.
\end{abstract}

[Keywords: BAK; IGFBP1; mitochondrial apoptosis; p53]

Supplemental material is available at http://www.genesdev.org.

Received May 2, 2007; revised version accepted September 28, 2007.

The mammalian p53 tumor suppressor protein serves as a critical coordinator of cellular responses to a wide variety of intrinsic and external stress signals (Oren 2003; Levine et al. 2006; Vousden and Lane 2007). The loss of p53 function contributes to the development and progression of many forms of cancer and, although less well understood, can also lead to pathologies in normal tissues. In response to any number of stresses, such as DNA damage, inadequate growth factor levels, or oncogene activation, the normally short-lived p53 protein is posttranslationally stabilized. This functionally engaged p53 protein then activates multiple signaling pathways, including those that can be growth inhibitory, proapoptotic, or even prosurvival. The actual cellular response that occurs is influenced by a number of factors. Among these are the cell type, the nature and degree of the activating signal, and whether the cells are normal or transformed. However, identifying the key elements that

${ }^{1}$ Corresponding author.

E-MAIL georged@mail.med.upenn.edu; FAX (215) 573-5892.

Article is online at http://www.genesdev.org/cgi/doi/10.1101/gad.1567107. define a particular p53-mediated stress response outcome remains a central, yet unresolved, question in the field. This issue is of practical importance, with direct implications for understanding normal physiologic events as well as for disease management in pathophysiologic settings.

The p53 protein is best characterized as a nuclear transcription factor, with the ability to positively or negatively modulate the expression of a variety of target genes, including some that are proapoptotic and others that promote survival (Laptenko and Prives 2006; Vousden and Lane 2007). In addition, however, data have accumulated that p53 also has a transcription-independent function in apoptosis induction (Caelles et al. 1994; Haupt et al. 1995; Chen et al. 1996; Ljungman et al. 1999; Chipuk et al. 2003; Speidel et al. 2006) with a direct apoptotic role at mitochondria (Marchenko et al. 2000; Dumont et al. 2003; Mihara et al. 2003; Chipuk et al. 2004; Leu et al. 2004; Arima et al. 2005; Strom et al. 2006). It is now well documented, for example, that during a p53-dependent apoptotic response, a fraction of cellular p53 protein rapidly translocates to mitochondria (Marchenko et al. 2000; Dumont et al. 2003; Mihara et 
al. 2003; Arima et al. 2005). Such p53 mitochondrial localization is not observed during p53-mediated cell cycle arrest, nor during p53-independent apoptosis. Additional evidence supporting p53's mitochondrial role is the observation that specifically targeting p53 to these cytoplasmic organelles, in the absence of detectable nuclear function, can induce a rapid apoptotic response in cells (Marchenko et al. 2000; Dumont et al. 2003; Mihara et al. 2003). Also, a study of a common polymorphism of p53 revealed that differences in apoptotic potential exhibited by two codon 72 variants correlate with their relative abilities to accumulate at mitochondria (Dumont et al. 2003). Interestingly, inhibition of RNA polymerase II-dependent transcription, which prevents p53mediated gene regulation, still induces a p53-dependent apoptotic response that correlates with p53 mitochondrial localization (Arima et al. 2005). Accumulating data of this kind underscore the need to better understand the regulation, and contribution, of p53's mitochondrial pathway to its cellular apoptotic functions, as well as to define how the transcriptional and nontranscriptional activities of p53 may be integrated to mediate the different p53-induced signaling events that occur in various cell types.

Although some mammalian cells and tissues, such as thymus and spleen, are very sensitive to p53-mediated apoptosis as a response to genotoxic stress, many others, including liver, tend to be much more resistant (Rubin and Casarett 1968; Gudkov and Komarova 2003; Ringshausen et al. 2006). In fact, p53 activation in isolated liver hepatocytes normally triggers cell cycle arrest (Ringshausen et al. 2006), while a cellular senescencelike program is the outcome in some murine liver carcinomas (Xue et al. 2007). Similarly, in one recent study of mice subjected to DNA damage, evidence of apoptosis in some tissues correlated positively with the accumulation of p53 at mitochondria; however, neither apoptosis nor mitochondrial p53 were detected in liver (Erster et al. 2004). It seems likely, therefore, that the mitochondrial role of p53 is regulated, context dependent, and modulated by the actions and/or abundance of yet-to-be-defined critical apoptosis regulators.

The extranuclear activities of p53 have been reported to involve its physical and/or functional interactions with certain members of the BCL2 protein family, including BAX, BAK, MCL1, BCL-xL, and BAD (Mihara et al. 2003; Chipuk et al. 2004, 2005; Leu et al. 2004; Jiang et al. 2006). In previous work employing affinity chromatography/mass spectrometry protocols, we identified BAK as a p53-interacting partner at mitochondria (Leu et al. 2004), a finding subsequently confirmed by others (Lomonosova et al. 2005; Moll et al. 2006; Pietsch et al. 2007; Sot et al. 2007). BAK is an integral outer mitochondrial membrane protein and a key cell death initiator (Griffiths et al. 1999; Wei et al. 2000; Sundararajan et al. 2001; Cuconati et al. 2003; Nijhawan et al. 2003; Gelinas and White 2005; Adams and Cory 2007). Commitment to apoptosis involves an activating conformational change in BAK, leading to formation of higher-order BAK multimers, mitochondrial membrane permeabilization, and the release of proapoptotic factors such as cytochrome c into the cytoplasm. The p53 protein can directly promote these mitochondrial alterations: Incubation of purified mitochondria with recombinant $\mathrm{p} 53$ protein results in BAK oligomerization and the release of cytochrome c from these organelles (Mihara et al. 2003; Leu et al. 2004). This p53-mediated cytochrome c release is dependent on the presence of BAK, since it fails to occur in BAK-deficient mitochondria (Leu et al. 2004). These data suggest that an interaction with BAK is an important component of p53's role at mitochondria.

In healthy cells, the proapoptotic function of BAK likely is held in check by interactions with prosurvival proteins, particularly certain anti-apoptotic members of the BCL2 family of proteins such as BCL-xL and MCL1 (Cuconati et al. 2003; Leu et al. 2004; Gelinas and White 2005; Willis et al. 2005, 2007; Shimazu et al. 2007). Indeed, overexpression of the BCL-xL protein is a common feature of many types of cancer, and correlates with enhanced resistance to death from chemotherapy or radiation treatment (Amundson et al. 2000). In light of all of these observations, we considered the possibility that hepatic cells may express one or more BAK-binding factors that can interfere with the mitochondrial role of p53. In a test of that hypothesis, we identified the liver factor IGFBP1 (insulin-like growth factor-binding protein-1) as a novel BAK-binding protein whose expression is induced following p53 activation. In turn, this activity of IGFBP1 antagonizes the mitochondrial p53 program and inhibits apoptosis.

\section{Results}

IGFBP1 is a BAK-binding protein up-regulated in response to p53 activation

Our initial studies on the mitochondrial p53 pathway included the use of HepG2 human hepatoma cells, which contain wild-type p53. We determined that these cells generally exhibit greater resistance to apoptosis induction by p53-activating agents than do many other cell types, although they exhibit no obvious defect in p53's transcriptional regulatory activities. As detailed below, we determined that apoptosis induction in these cells can be promoted by conditions that inhibit transcription and promote $\mathrm{p} 53$ 's mitochondrial functions. Consequently, we investigated whether the mitochondrial p53 pathway in these cells might be antagonized by the presence of a p53-induced BAK-binding survival protein. In a test of this idea, we affinity-purified BAK-interacting proteins in HepG2 cells both before and after treatment with Nutlin-3. Nutlin-3 is a small molecule that binds to the E3 ubiquitin ligase, MDM2, which is a critical negative regulator of p53. Nutlin-3 inhibits the interaction between these proteins, and leads to an increase in p53 abundance and activity in a nongenotoxic manner (Vassilev et al. 2004). Among the potential BAK-binding proteins eluted following p53 activation, we focused on a prominent species with a relative molecular mass of $\sim 30$ 
kDa (Fig. 1A). Liquid chromatography-tandem mass spectrometry analysis of this band identified eight tryptic peptides derived from the human IGFBP1. While IGFBP1 levels increased following p53 activation of the HepG2 cells, there was no change in the relative abundance of the anti-apoptotic BCL2 family proteins MCL1 or BCL-xL (Fig. 1B). Using immunoprecipitation (IP)Western blot analysis, we confirmed that endogenous BAK forms a complex with endogenous IGFBP1 (Fig. 1C). The specificity of the interaction between these proteins also was supported by in vitro binding assays (Supplementary Fig. S1A,B). Additionally, IGFBP1 colocalized and cofractionated with BAK, based on immunofluorescence (Fig. 1D) and subcellular fractionation analyses (Supplementary Fig. S1C), respectively.

The elevated expression of IGFBP1 in HepG2 cells following Nutlin-3 treatment suggested that the IGFBP1 gene may be a transcriptional target of p53 in hepatic cells. Moreover, the pattern of IGFBP1 up-regulation occurred with kinetics similar to that of established p53 direct targets, such as the activated genes $m d m 2$, p21/ waf1/cdkn1a, and puma- $\alpha$, as well as the repressed gene survivin (Fig. 1E). Additionally, we only noted induction of IGFBP1 mRNA and protein expression in HepG2, but not in Huh7 hepatoma cells with mutated p53 (Fig. 1F) or in the p53-null Hep3B hepatoma cell line (data not shown). IGFBP1 induction also is impaired in HepG2 cells stably expressing human papillomavirus E6 protein (HPV16), which mediates p53 degradation (Fig. 1G). In addition to Nutlin-3, other agents that activate p53, such as the chemotherapeutic drugs cisplatin (cis-diamminedichloroplatinum II) and doxorubicin (adriamycin), also enhance IGFBP1 abundance in HepG2 cells (Supplementary Fig. S2A). Together, these results provide evidence that IGFBP1 RNA and protein expression are upregulated in response to p53 transcriptional activation. However, it remains to be determined whether the IGFBP 1 gene is a direct $\mathrm{p} 53$ target or whether its expression is activated indirectly in response to p53 actions. Also, since IGFBP1 is known to be up-regulated in response to a wide variety of cell stresses and physiologic conditions (Lee et al. 1997), it is very likely that its expression is regulated in both a p53-dependent and p53independent fashion.

The discovery that IGFBP1 targets to mitochondria and forms a complex with BAK was intriguing for a number of reasons. First, IGFBP1 is an early-response hepatic factor that is rapidly induced in both humans and rodents following a number of stress-related events, including infection, surgical resection, toxic damage, and fasting (Lee et al. 1997; Leu et al. 2001, 2003a,b; Scharf et al. 2004; White et al. 2005). IGFBP1 is one of six members of a family of serum proteins best characterized by their ability to bind to and modulate the bioavailability of circulating insulin-like growth factors (IGFs). However, many recent studies have documented that these IGFBP proteins also have important intracellular functions that are independent of, and unrelated to, their secretion and interactions with the IGFs (Lee et al. 1997; Duan and $\mathrm{Xu}$ 2005). One such example is provided by IGFBP3, a widely expressed protein that inhibits growth or promotes apoptosis in several ways, and has IGF-independent functions in the nucleus and cytoplasm (Firth and Baxter 2002; Cohen 2006). Unlike IGFBP3, IGFBP1 is
A

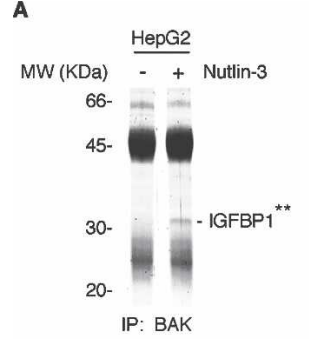

E

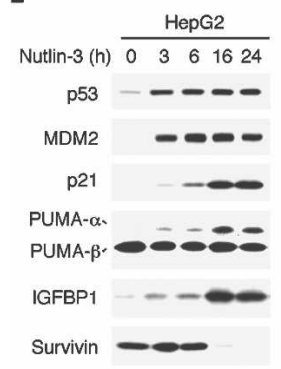

B

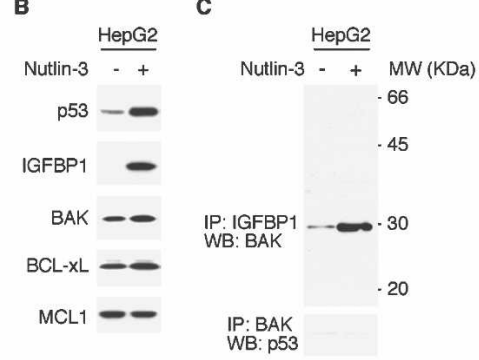

$\mathbf{F}$

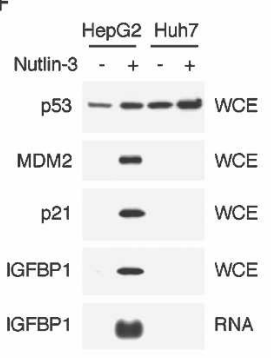

D

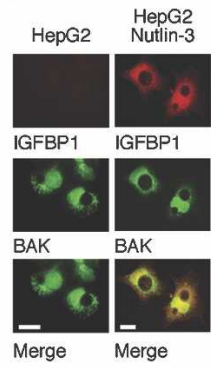

G

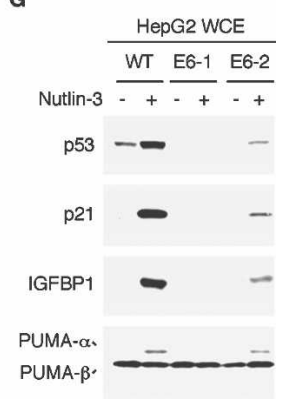

Figure 1. IGFBP1 is a p53-induced BAK-binding protein. $(A)$ Whole-cell extracts (WCE) prepared from HepG2 cells before or after $10 \mu \mathrm{M}$ Nutlin-3 treatment were immunoprecipitated using an anti-BAK antibody. The excised band of $\sim 30 \mathrm{kDa}$ shown in the Coomassie gel contained the following IGFBP1 peptide sequences $\left(^{\star \star}\right)$ : IPGSPEIR, NGFYHSR, ALHVTNIK, ALHVTNIKK, RIPGSPEIR, AQETSGEEISK, IELYRVVESLAK, and ALPGEQQPLHALTR. (B) Western blot analysis shows induction of IGFBP1 protein, but not BCL-xL or MCL1, in Nutlin-3treated HepG2 cells. (C) IP-Western blot (WB) analysis of WCE from Nutlin-3-treated HepG2 cells shows that BAK interacts with IGFBP1, but not p53. (D) HepG2 cells were examined using immunofluorescent microscopy for IGFBP1 protein (red) and BAK protein (green). The merged image provides evidence of colocalization of these proteins (yellow). Bars, 20 $\mu \mathrm{m}$. (E) HepG2 cells were treated with $10 \mu \mathrm{M}$ Nutlin-3 for the indicated times, protein extracts were prepared, and Western blot analysis was used to determine expression of the proteins indicated. $(F)$ Nutlin-3-treated HepG2 (wild-type p53) or Huh7 (mutant p53) hepatoma cells were examined for the proteins or RNA indicated. $(G)$ Western blots of protein extracts prepared following Nutlin-3 treatment of the parental HepG2 cells and two independent clones (E6-1 and E6-2) that stably express the HPV-E6 protein. 
expressed in a tissue-restricted manner, having been detected primarily in liver hepatocytes, decidualized endometrium, and at low levels in kidney (Lee et al. 1997; Duan and Xu 2005). IGF ligands, such as IGF1, bind to IGF receptors in pathways that regulate cellular proliferation, cell cycle progression, and/or apoptosis. However, it is important to note that normal adult liver hepatocytes have negligible levels of IGF-1R receptors, and the IGFs are thought to have little effect on the normal growth or metabolism of the liver (Sjögren et al. 1999; Skrtic et al. 2001). On the contrary, investigations carried out using transgenic and gene knockout animal models have indicated that IGFBP1 has prosurvival functions within the liver that signal through IGF-independent pathways (Leu et al. 2003b; Lu and Archer 2003). Also, in an initial characterization of IGFBP1-null mice, the absence of IGFBP1 in livers correlated with enhanced caspase activation and proteolytic cleavage of caspase substrates such as MMP-9 and TGF- $\beta$ following hepatic insults (Leu et al. 2003b). However, in those earlier studies, an underlying molecular explanation for such observations was not available (Leu et al. 2003a,b; Lu and Archer 2003). The identification of IGFBP1 as a novel BAK-binding protein now suggests a potential mechanistic basis for its intracellular cytoprotective role.

IGFBP1 expression interferes with apoptosis induction and p53 mitochondrial accumulation

In evaluating the actions of endogenous IGFBP1 in modulating apoptosis in the HepG2 cells, we attempted to use small interfering RNA (siRNA) technology to reduce IGFBP1 expression following p53 activation; however, given the robust IGFBP1 induction, this approach produced only a modest decrease in IGFBP1 levels (data not shown). As an alternative strategy, therefore, we treated the cells with increasing amounts of cisplatin (3.5-50 $\mu \mathrm{M})$ and asked whether this would elicit a dosedependent inhibition of IGFBP1 that related to HepG2 survival. We chose this approach because, while cisplatin results in formation of inter- and intrastrand cross-links that inhibit DNA replication, this drug also inhibits RNA polymerase II-mediated transcription in a dose-dependent fashion (Cullinane et al. 1999; Jung and Lippard 2006). In addition, the use of higher doses of cisplatin $(35-50 \mu \mathrm{M})$ has been reported to induce apoptosis in hepatoma cell lines such as HepG2 in a manner that is dependent on the presence of wild-type p53 protein (Muller et al. 1997; Qin and Ng 2002). Therefore, the HepG2 cells were treated with several concentrations of cisplatin, all of which stabilized p53 to comparable levels (Fig. 2A). At the lower doses (3.5-30 $\mu \mathrm{M})$, cisplatin did not inhibit transcription, but led to increased expression of the IGFBP1 and p21 proteins (Fig. 2A). Also, the IGFBP1 protein colocalized (Fig. 2B; Supplementary Fig. S2B) and coimmunoprecipitated (Fig. 2C,D; Supplementary Fig. S2C) with BAK; in the presence of IGFBP1, there was negligible apoptosis (Fig. 2E,F; Supplementary Fig. $\mathrm{S} 2 \mathrm{D})$. In contrast, at the higher concentrations of cisplatin $(40-50 \mu \mathrm{M})$, there was little if any IGFBP1 protein expressed (Fig. 2A,E; Supplementary Fig. S2A,D). In the absence of IGFBP1, the p53 protein complexed with BAK (Fig. 2D; Supplementary Fig. S2C,D); this correlated with the induction of apoptosis in the HepG2 cells (Fig. 2E,F; Supplementary Fig. S2A,D). Induction of apoptosis in these cells was indicated by cleavage of caspase-3 (Fig. 2E; Supplementary Fig. S2D), a major executioner caspase in the mitochondrial apoptotic pathway, and by cleavage of PARP (Fig. 2E; Supplementary Fig. S2A,D), a cellular substrate of activated caspase-3, as well as by Annexin V staining (Fig. 2F). It is also worth pointing out that PUMA- $\alpha$, a crucial mediator of mitochondrial p53 activities in certain cell types (Jeffers et al. 2003; Villunger et al. 2003; Chipuk et al. 2005), was up-regulated following the lower $(3.5 \mu \mathrm{M})$ dose of cisplatin (Fig. 2A; Supplementary Fig. S2D); yet, in the presence of IGFBP1, this was not sufficient to induce apoptosis (Fig. 2E,F; Supplementary Fig. S2D). Previous investigations also have found that liver hepatocytes and other cell types can remain refractory to $\mathrm{p} 53$-mediated apoptosis despite a potent induction of PUMA (Ringshausen et al. 2006; Speidel et al. 2006; Xue et al. 2007). Similar to the results obtained with cisplatin, doxorubicin also induced apoptosis in the HepG2 cells in a dose-dependent fashion that negatively correlated with expression of IGBFP1 (Supplementary Fig. S2A,E). Overall, the data revealed that an interaction between IGFBP1 and BAK at mitochondria inversely correlates with the formation of a p53/BAK complex and apoptosis induction in these cells.

The above findings prompted us to further investigate the mitochondrial actions of p53 under conditions that would preclude the up-regulation of IGFBP1 or other potential survival factors. For these studies, we employed $\alpha$-amanitin, a specific inhibitor of RNA polymerase IImediated transcription. We chose this compound because previous work has shown that $\alpha$-amanitin induces caspase-mediated apoptosis in a manner that is both p53 dependent and correlates with the accumulation of p53 at mitochondria (Arima et al. 2005). Because $\alpha$-amanitin is not readily taken up by cultured cells (Ljungman et al. 1999|, we carried out these studies over a 24- to 48-h time period. As expected, the p53 target genes MDM2 and IGFBP1 were not induced in the presence of this transcription inhibitor, and the abundance of PUMA clearly decreased (Fig. 2G,H). Consistent with its effects on other cell lines, $\alpha$-amanitin induced caspase-mediated apoptosis in the HepG2 cells, as indicated by the appearance of cleaved forms of caspase- 8 and caspase-3, as well as by the accumulation of Annexin V-positive cells (Fig. $2 \mathrm{H}, \mathrm{I})$. Notably, the induction of apoptosis correlated with p53 mitochondrial localization (Fig. 2J) and its interaction with BAK (Fig. 2K).

These data indicated that in the HepG2 cells, the apoptosis induced by high-dose cisplatin, or $\alpha$-amanitin, was not dependent on p53-mediated transcription, but correlated with an active mitochondrial p53 pathway. Thus, we next tested whether inhibiting the ability of p53 to localize to mitochondria would provide protection against the cell death induction. To this end, we utilized pifithrin- $\mu$ (PFT- $\mu$ ), a recently identified small 
A

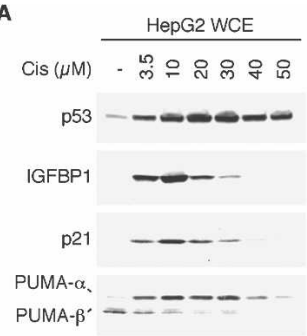

D

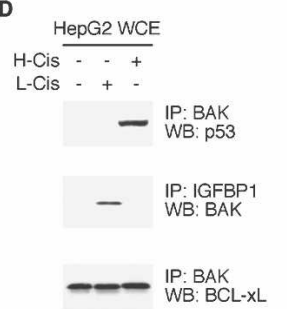

B

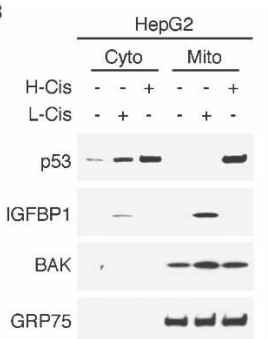

E

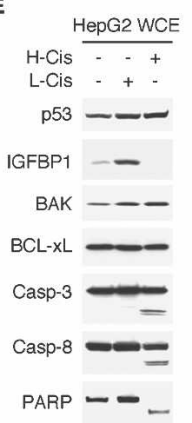

c
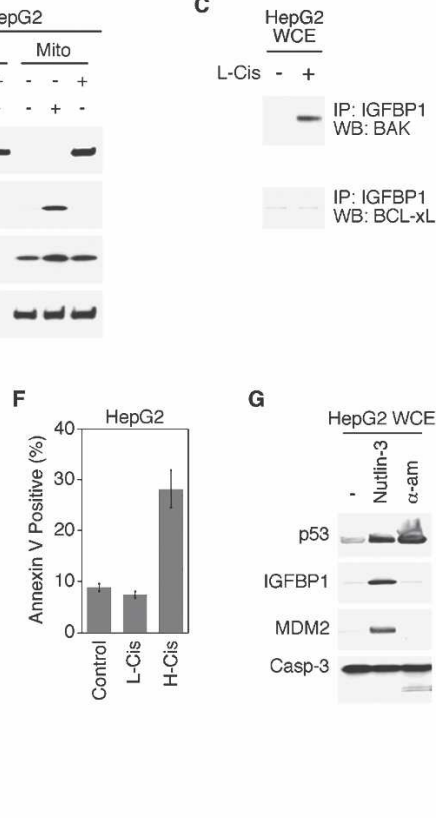

G

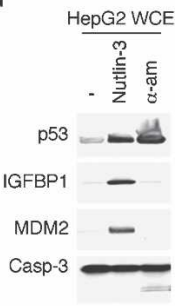

Casp-3
J

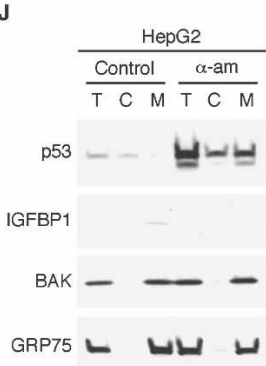

பய ப
K

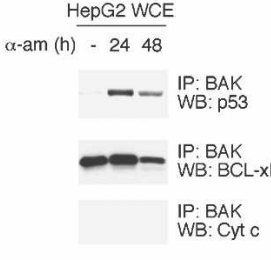

H

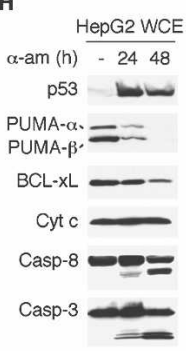

1

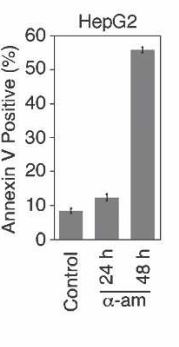

by immunoblotting for the proteins indicated. $(K)$ IP-Western blot analysis reveals that endogenous p 53 interacts with BAK after exposure to $\alpha$-amanitin for the indicated times. In contrast, no interaction between cytochrome c (Cyt c) and BAK was noted.

molecule that was reported (Strom et al. 2006) to inhibit p53-dependent apoptosis by interfering with the ability of p53 to accumulate at mitochondria; however, this compound has no discernable effect on p53-dependent transactivation (see Fig. 3A), or p53-independent apoptosis. In the presence of PFT- $\mu$, p53 did not accumulate at mitochondria following cisplatin treatment of the HepG2 cells (Fig. 3B), and therefore was not able to interact with BAK (Fig. 3C; Supplementary Fig. S2F). Concomitantly, PFT- $\mu$ markedly suppressed apoptosis induction by high-dose $(50 \mu \mathrm{M})$ cisplatin in these cells (Fig. 3D).

\section{p53's mitochondrial role is mediated by $B A K$ binding}

The above studies reinforced the conclusion that an interaction with mitochondrial BAK is important for p53's mitochondrial role in the induction of apoptosis. These data also raised the question of whether p53, which lacks obvious mitochondrial targeting domains, would still accumulate at mitochondria in the absence of BAK binding. To address this question, we prepared cultures of primary mouse embryonic fibroblasts (MEF) from mouse embryonic day 13.5 (E13.5) BAK-null animals and wildtype controls. Consistent with previous observations (Ljungman et al. 1999), high-dose cisplatin (50 $\mu \mathrm{M})$ elicited an apoptotic response in the wild-type MEFs; however, this cell death response was markedly attenuated in the BAK-null cells. The difference in apoptosis exhibited by these cells was evident by immunoblot analysis of cleaved caspase- 3 and PARP (Fig. 3E), as well as by TUNEL assays (Fig. 3F,G). Correspondingly, the apoptosis induction in the wild-type MEFs correlated with p53 mitochondrial localization (Fig. $3 \mathrm{H}$ ) and formation of a p53/BAK complex (Fig. 3I). In contrast, there was negligible mitochondrial p53 accumulation in the $B A K$-null cells (Fig. 3H), despite the mitochondrial presence of the proapoptotic protein BAX (Fig. $3 \mathrm{H})$. Perhaps because they are compromised in their apoptotic response, a portion of the BAK-null cells expressed senescence-associated $\beta$-galactosidase, both before and after cisplatin treatment (Supplementary Fig. S3A,B); however, further studies are needed to determine the underlying molecular mechanisms involved, including whether this is p53 depen- 
Figure 3. Interaction between $\mathrm{p} 53$ and BAK is required for apoptosis induction. (A) HepG2 cells were either untreated or pretreated with PFT- $\mu(20 \mu \mathrm{M})$ for $1 \mathrm{~h}$, followed by the addition of $50 \mu \mathrm{M}$ cisplatin (H-Cis) for $22 \mathrm{~h}$; Western blot analysis examined the proteins indicated. (B) Mitochondrial (Mito) fractions were isolated from HepG2 cells that were either untreated or pretreated with PFT- $\mu(20 \mu \mathrm{M})$ for $1 \mathrm{~h}$, followed by the addition of $50 \mu \mathrm{M}$ cisplatin (H-Cis) for $22 \mathrm{~h}$. Western blots analyzed the proteins indicated. $(C)$ IP-Western blot (WB) analysis confirms the presence of a p53/BAK complex in whole-cell extracts (WCE) prepared from cisplatin-treated HepG2 cells indicated in $A$. (D) Samples in $A$ were examined by immunoblotting for the proteins indicated. The cleaved products of caspase-3 and caspase- 8 are marked with arrows. $(E)$ WCE prepared from primary MEFs (wild type or $B A K^{-/-}$) either untreated or treated with cisplatin $(50 \mu \mathrm{M}, 15 \mathrm{~h})$ were examined for the proteins indicated. The cleaved products of caspase-3 and PARP are marked with arrows. (F) TUNEL staining of primary MEFs (wild type or $\left.B A K^{-/-}\right)$, either before or after cisplatin $(50 \mu \mathrm{M}, 15 \mathrm{~h})$ treatment. The brown staining indicates positive TUNEL staining. Bars, $50 \mu \mathrm{m}$. (G) Quantification of TUNEL-positive cells in MEFs from $F$. Average of eight random 20x fields \pm SD. $(H)$ Mito fractions prepared from the same samples indicated in $E$ were examined by immunoblotting for the proteins indicated. (I) IP-Western blot analysis confirms the presence of an p53/BAK complex in WCE prepared from the cisplatin-treated wild-type MEFs indicated in $E$.
A

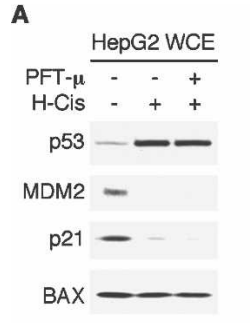

D

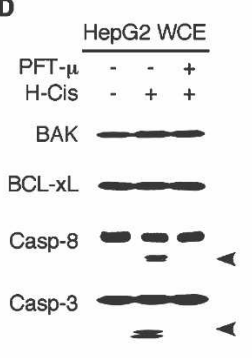

G

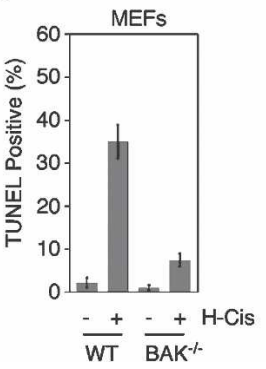

B

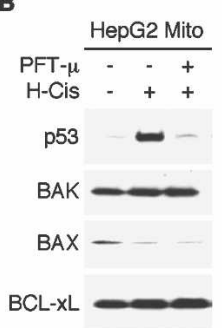

E

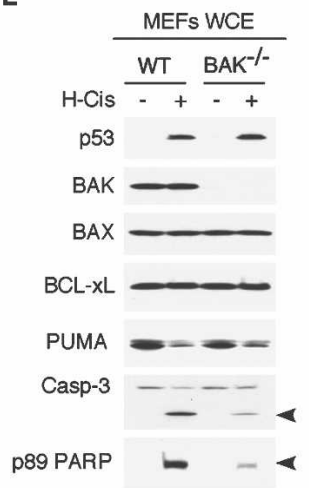

H

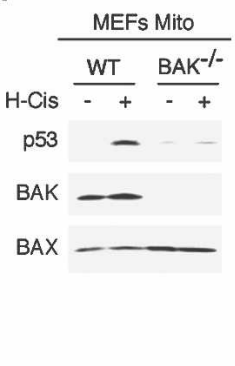

$\mathbf{F}$
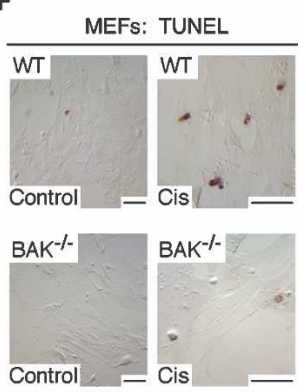

C

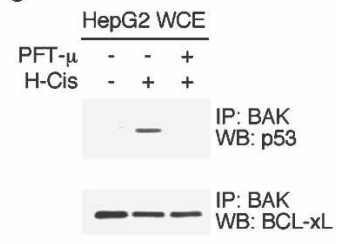

Contro

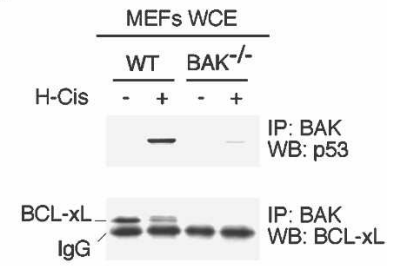

dent. Together with previous investigations (Leu et al. 2004; Pietsch et al. 2007), the results of these analyses using primary untransformed cultures of MEFs provide support for the idea that, at least in some cell types, the relative abundance and/or the accessibility of BAK is a critical factor in $\mathrm{p} 53$ 's mitochondrial program.

\section{p53's mitochondrial role is antagonized by IGFBP1}

We then tested whether the overexpression of IGFBP1 by itself would alter p53-mediated apoptosis in nonhepatic cell types. We stably expressed IGFBP1 in the U2OS human osteosarcoma cells and in MCF7 human breast carcinoma cells, two cell lines that exhibit apoptosis-related p53 mitochondrial localization and BAK binding in response to genotoxic stress (Fig. 4A; Supplementary Fig. S4A,B). The exogenously expressed IGFBP1 in the U2OS and MCF7 cells coimmunoprecipitated with (Fig. 4B; data not shown), colocalized with (Fig. 4C), and cofractionated with BAK (Fig. 4D; data not shown). When compared with the parental cells, the IGFBP1-expressing U2OS and MCF7 cells also exhibited enhanced resis- tance to apoptosis induction in response to the anti-cancer drugs cisplatin or doxorubicin, as indicated by attenuation in PARP cleavage (Fig. 4D; Supplementary Fig. S4B). We noted that, following extended exposure to high levels of the DNA damaging agents, there was a reduction in the expression of IGFBP1 protein that correlated with a delayed appearance of p53 at mitochondria together with the proteolytic cleavage of PARP (Fig. 4D; Supplementary Fig. S4B). A similar correlation between the changes in IGFBP1 expression levels and the existence of a temporally limited protection against death signaling in vivo was reported previously (Leu et al. 2003b). Consequently, stress signaling events that modulate IGFBP1 expression would be expected to have an important influence on the timing and extent of this protein's cytoprotective actions.

To better understand the mechanism by which IGFBP1 antagonizes p53-mediated apoptosis, we investigated whether, in a cell-free system, IGFBP1 can interfere with p53's ability to bind to BAK. We also examined whether the mitochondrial presence of IGFBP1 affects the ability of p53 to promote an activating conforma- 
A

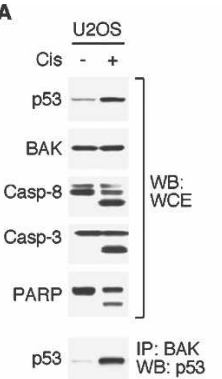

B

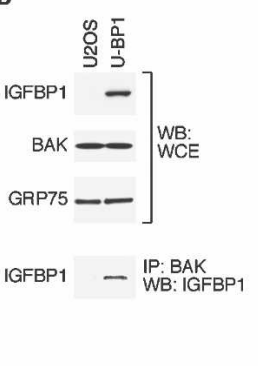

C

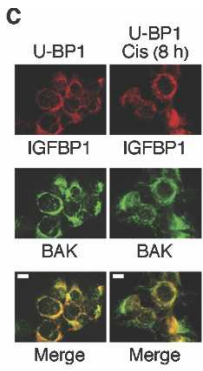

D

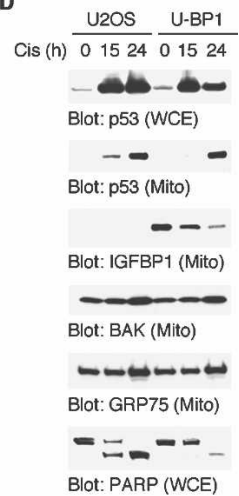

Figure 4. Exogenous IGFBP1 expression interferes with mitochondrial accumulation of p53, p53/BAK interaction, and p53-mediated BAK oligomerization. (A) Western blot (WB) analysis shows cleavage of caspase-8, caspase-3, and PARP in whold-cell extracts (WCE) prepared from U2OS treated with cisplatin $(50 \mu \mathrm{M}, 24 \mathrm{~h})$. Note these antibodies detect both intact (top) and cleaved (bottom) forms of these proteins. IP-Western blots show a p53/BAK complex in U2OS treated with cisplatin $(50 \mu \mathrm{M}, 24 \mathrm{~h}) .(B)$ IP-Western blot analysis reveals that IGFBP1 interacts with BAK in U2OS stably expressing exogenous IGFBP1 (U-BP1 cells). (C) Immunofluorescence analysis of U-BP1 cells for IGFBP1 protein (red) and BAK protein (green) before and after cisplatin (50 $\mu \mathrm{M}, 8 \mathrm{~h})$. The merged image indicates colocalization of IGFBP1 with BAK (yellow). Bars, $20 \mu \mathrm{m}$. (D) Western blots of the indicated proteins in WCE or mitochondrial fractions (Mito) prepared from untreated or cisplatin-treated $(50 \mu \mathrm{M}, 15 \mathrm{~h}$ or $24 \mathrm{~h}) \mathrm{U} 2 \mathrm{OS}$ and U-BP1 cells. Note cleaved PARP is not detected in U-BP1 cells until $24 \mathrm{~h}$ following high dose of cisplatin, which blocks transcription (Cullinane et al. 1999; Jung and Lippard 2006). (E) Western blots of the indicated proteins in Mito fractions prepared from HepG2 cells, untreated or treated with Nutlin-3 (10 $\mu \mathrm{M}, 24 \mathrm{~h})$. (F) Mito prepared from HepG2 cells untreated or treated with $10 \mu \mathrm{M}$ of Nut-

lin-3 were incubated with $50 \mathrm{ng}$ of purified p53 recombinant protein followed by IP-Western analyses. (G) The same samples (20 $\mu \mathrm{g})$ indicated in $E$ were incubated with $0,5,25$, or $100 \mathrm{pmol}$ of purified p53 recombinant protein. The reactions were cross-linked with $5 \mathrm{mM} \mathrm{BMH}$ (the uncleavable protein cross-linker 1,6-bismaleimidohexane) followed by Western analysis using an anti-BAK antibody (a conformation-specific antibody directed to the $\mathrm{N}$ terminus).

tional change in BAK, since our previous investigations confirmed that an interaction with BAK is needed for p53 to induce BAK oligomerization (Leu et al. 2004; Pietsch et al. 2007). For these studies, we used a well-established in vitro assay (Wei et al. 2000), as we described previously (Leu et al. 2004; Pietsch et al. 2007). In this case, we compared the relative ability of p53 to bind to BAK and to induce BAK oligomerization in the presence or absence of IGFBP1. In one approach, we incubated recombinant p53 protein with mitochondria that were purified either from control HepG 2 cells or from cells that had been treated with Nutlin-3 to induce mitochondrial accumulation of IGFBP1 (Fig. 4E). The results showed that when mitochondria contain IGFBP1, the amount of p53 coimmunoprecipitating with BAK is clearly reduced (Fig. 4F; Supplementary Fig. S4C). Moreover, mitochondria from IGFBP1-expressing HepG2 cells displayed a dose-dependent resistance to the p53-mediated BAK oligomerization (Fig. 4G; Supplementary Fig. S4D). Similarly, when these assays were carried out using mitochondria isolated from either the parental controls or IGFBP1-expressing U2OS (U-BP1) cells (Supplementary Fig. S4E), a p53-mediated change in BAK conformation was attenuated when the mitochondria contained IGFBP1 (Supplementary Fig. S4F). These data suggest a model in which, at least for some cell types, the relative ability of the p53 protein to target to mitochondria and form a complex with BAK is a key determinant of its proapoptotic actions. Moreover, the enhanced ex- pression of BAK-sequestering prosurvival factors, such as IGFBP1, can inhibit this function of p53.

\section{IGFBP1 binds to BAK in mouse livers following $a$ variety of hepatic insults}

To further characterize the prosurvival role of IGFBP1, we turned to the use of mouse models. Both intracellular and secreted forms of IGFBP1 have been described in human liver-derived cells and in rodent livers (Leu et al. 2001, 2003a,b; Scharf et al. 2004; Marchand et al. 2006). First, we confirmed the presence of IGFBP1 in both of these locations in human HepG2 cultures following its induction with Nutlin-3 or with low-dose cisplatin (Fig. 5A). We also examined the localization of hepatic IGFBP1 in the wild-type mouse in response to a variety of stimuli previously shown to up-regulate the expression of this protein (Lee et al. 1997; Leu et al. 2001, 2003b). As expected, IGFBP1 was present in both the serum samples, as well as in the liver mitochondrial fractions, after overnight fasting $(24 \mathrm{~h})$ of the animals, as well as after a 90-min, nonlethal dose of the following: epidermal growth factor (EGF), cisplatin, or anti-Fas agonist (also known as Fas mAb) (Fig. 5B). In fact, following exposure to Fas $\mathrm{mAb}$, the majority of the IGFBP1 was intracellular (Fig. 5B). The intracellular IGFBP1 protein coimmunoprecipitated with BAK in liver extracts prepared from mice exposed to each of these IGFBP1-inducing conditions (Fig. 5C), a finding that is in accordance with 
Figure 5. IGFBP1 binds to BAK in mouse liver. $(A)$ Western blots of whole-cell extracts (WCE) or culture media (Media) prepared following $10 \mu \mathrm{M}$ Nutlin-3 or $3.5 \mu \mathrm{M}$ cisplatin (L-Cis) treatment of the HepG2 cells. $(B)$ Western blots show that IGFBP1 protein is induced and present in both Sera and mitochondrial (Mito) fractions of IGFBP1 $1^{+/+}\left(B P 1^{+/+}\right)$ mice after overnight fasting, or after a 90-min treatment with each of the following: EGF, Fas mAb, or cisplatin. The cisplatin results are from two different mice. $(C)$ IP-Western blots confirm the presence of an IGFBP1/BAK complex in liver WCE prepared from the same samples indicated in $B$. The results shown are representative of the analysis of at least three mice per genotype. $(D)$ Western blot of proteins from WCE prepared from untreated IGFBP $1^{+/+}$ $\left(B P 1^{+/+}\right)$and IGFBP1 $1^{-/-}\left(B P 1^{-/-}\right)$livers. (E) Western blot of proteins from Mito fractions prepared from untreated $\mathrm{BP}^{+/+}$and $B P 1^{-/-}$livers. (F) IP-Western blot analysis confirms the presence of an p53/BAK complex in WCE prepared from untreated $B P 1^{-/-}$ liver indicated in $D$. $(G)$ Proteins from liver WCE of control (untreated) $B P 1^{+/+}$and $B P 1^{-/-}$mice were examined by Western blotting for the proteins indicated. $(H)$ Proteins from liver Mito of control (untreated) $\mathrm{BP}^{+/+}$and $\mathrm{BP}^{-/-}$mice were cross-linked with $5 \mathrm{mM}$ BMH followed by Western analysis using an anti-BAK antibody. In addition to the BAK monomer $\left({ }^{\star}\right)$, BAK aggregates $\left({ }^{\star \star}\right)$ were detected in untreated IGFBP1-deficient livers.
B
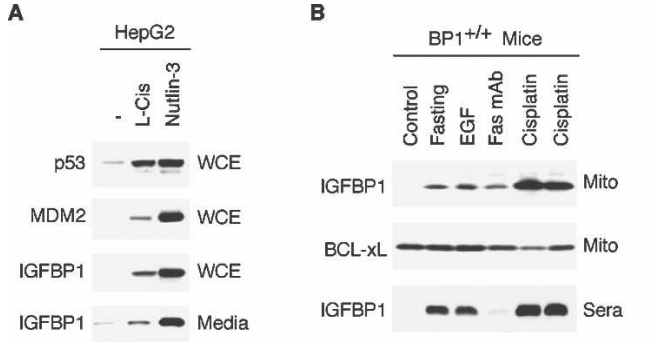

C
D

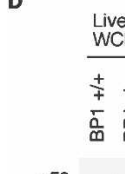

B

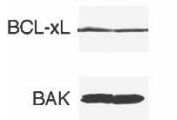

E

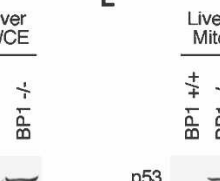

\begin{tabular}{l} 
Liver \\
Mito \\
\hline$+\frac{1}{+}+$ \\
$\frac{1}{0} \frac{1}{0}$
\end{tabular}

$\mathbf{F}$

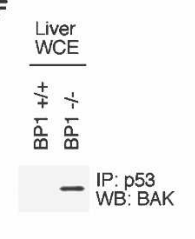

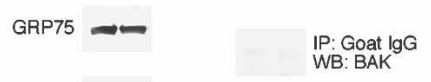

HSP60 - - $\therefore$

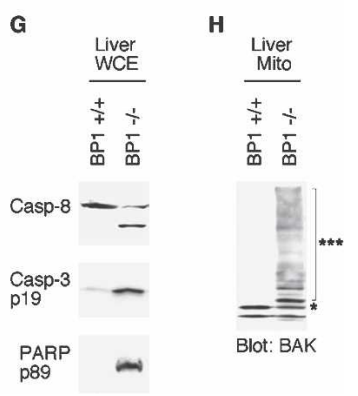

the data obtained in our experiments with both HepG2 and the IGFBP1-expressing nonhepatic cell lines, described above. In contrast to the up-regulation of IGFBP1, there was no consistent change in BCL-xL protein levels (Fig. 5B).

\section{IGFBP1 regulates the mitochondrial actions of p53 in $v i v o$}

To gain additional insight into the physiological role of IGFBP1, and to investigate whether the expression of this hepatic protein acts as a modulator of the p53 mitochondrial pathway of apoptosis in liver, we employed IGFBP1 knockout mice. An initial characterization of livers from the IGFBP $1^{-/-}$mice had revealed the presence of chronic low-level spontaneous apoptosis, but the molecular basis for this observation was not defined (Leu et al. 2003b). Because secreted IGFBP1 protein binds to IGF1 and changes in circulating IGF1 may affect apoptotic signaling (Lee et al. 1997; Duan and Xu 2005), we tested for possible differences in circulating IGF1 levels that might contribute to the phenotype of these animals. The serum IGF1 levels in untreated IGFBP1-/- $(n=4)$ and $I G F B P 1^{+/+}(n=3)$ mice were $0.99 \pm 0.13 \mathrm{ng} / \mathrm{mL}$ and $0.9 \pm 0.07 \mathrm{ng} / \mathrm{mL}$, respectively, thus showing no significant differences.

In cultured cells, IGFBP1's interaction with BAK interferes with p53's mitochondrial activities; thus, we were prompted to examine the subcellular distribution of p53 in livers of untreated IGFBP1 $1^{-/-}$animals. First, we noted that the relative abundance of p53 protein in quiescent livers of IGFBP1 $1^{-/-}$mice was higher than that in livers of untreated controls (Fig. 5D). We also were struck by the finding that, in contrast to the situation in wild-type animals, the p53 protein was present in purified mitochondrial fractions isolated from livers of untreated IGFBP1 $1^{-/-}$mice (Fig. 5E). The liver is a major detoxifying site in the body that is continuously exposed to potentially damaging agents; thus, even under normal physiologic conditions, some proportion of hepatocytes are subject to oxidative and metabolic stresses and/or genotoxic damage - conditions that might be expected to contribute to p53 activation. Consistent with that idea, the IGFBP $1^{-/-}$livers contained a p53/BAK complex (Fig. $5 \mathrm{~F}$ ) and evidence of apoptosis, as revealed by the presence of cleaved forms of caspase-8, caspase-3, and PARP (Fig. 5G). Higher-order aggregates of BAK, consistent with BAK activation, also were present (Fig. 5H). These results point to a role for IGFBP1 in helping to maintain at least a portion of the proapoptotic BAK in an "inactive" configuration, thereby protecting the liver from apoptosis under physiologic conditions.

To gain additional insight into the physiological role of IGFBP1, and to investigate the impact of p53 mitochondrial pathway of apoptosis in liver following DNA damage, the wild-type and IGFBP1 $1^{-/}$mice were intraperitoneally injected with cisplatin. This led to a robust accumulation of mitochondrial IGFBP1 (Figs. 5B, 6A) and formation of an IGFBP1/BAK complex (Fig. 5C) in the wild-type livers, and there was little evidence of liver damage or apoptosis (Fig. 6B,C). In contrast, the cisplatin-treated IGFBP1 $1^{-/}$livers exhibited much more hepatocellular injury and prominent histological features of apoptosis (Fig. 6D-G). At $1 \mathrm{~h}$ (Fig. 6E) or $3 \mathrm{~h}$ (Fig. 6F,G) post-cisplatin treatment, evidence of a greater degree of cellular condensation, hypereosinophilic cytoplasm, and 
A

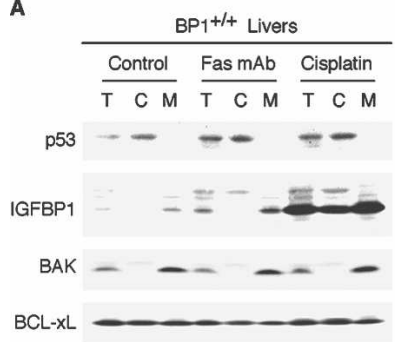

H

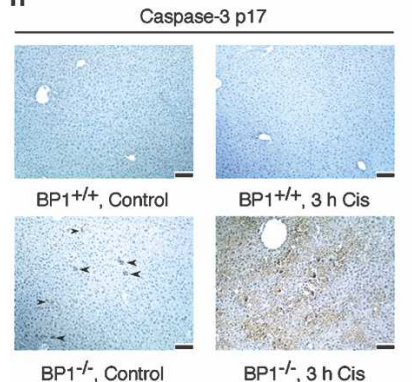

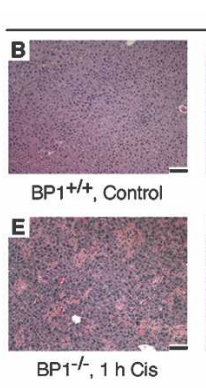
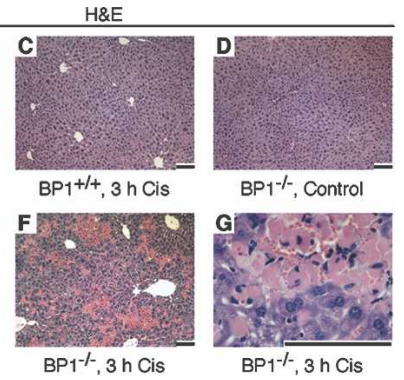

I

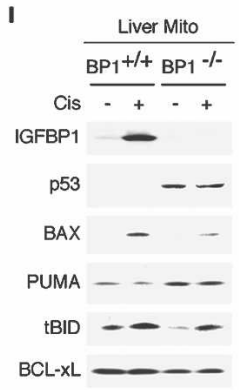

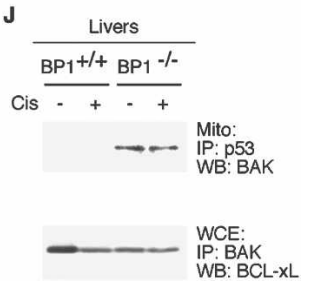

WB: BCL-XL

Figure 6. Increased injury and apoptosis after acute cisplatin treatment in IGFBP $1^{-/-}$livers. (A) Total $(T)$, cytosolic $(C)$, and mitochondrial (M) liver extracts were examined by Western blot for the proteins indicated, following a 90-min treatment of the animals with cisplatin or Fas mAb. The internal control BCL-xL is present in both cytosolic and $\mathrm{mi}$ tochondrial fractions. $(B-G)$ Hematoxylin and eosin $(\mathrm{H} \& \mathrm{E})$ staining of control $B P 1^{+/+}$liver $(B), B P 1^{+/+}$ liver $3 \mathrm{~h}$ after cisplatin (Cis) injection $(C)$, control $B P 1^{-/-}$liver $(D), B P 1^{-/-}$liver $1 \mathrm{~h}$ after cisplatin challenge $(E), B P 1^{-/-}$liver $3 \mathrm{~h}$ after cisplatin exposure $(F)$, and $B P 1^{-/-}$liver $3 \mathrm{~h}$ after cisplatin treatment $(G) . F$ is enlarged in $G$ to show greatly enhanced hepatocellular injury and prominent histological features of apoptosis (i.e., cellular condensation, hypereosinophilic cytoplasm, and aggregation of chromatin at the nuclear membrane) in the $B P 1^{-/-}$livers $3 \mathrm{~h}$ following acute cisplatin exposure. Bars, $100 \mu \mathrm{m} .(H)$ Immunohistologic staining of control $B P 1^{+/+}$liver, control $B P 1^{-/-}$liver, $B P 1^{+/+}$liver $3 \mathrm{~h}$ after cisplatin injection, and $B P 1^{-/-}$liver $3 \mathrm{~h}$ after cisplatin challenge using anti-caspase- 3 p17 antibody. The brown staining indicates positive anti-caspase- 3 p17 staining. Arrowheads in control $\mathrm{BP}^{-/-}$liver indicate positive anti-caspase-3 p17 staining. Bars, $100 \mu \mathrm{m}$. (I) Western blot of proteins from mitochondrial (Mito) fractions prepared from control and cisplatin-treated $B P 1^{+/+}$and $B P 1^{-/-}$livers. (J) IP-Western blot analysis reveals that Mito p53 interacts with BAK in both untreated and cisplatin-treated $B P 1^{-1-}$ livers. In contrast, formation of a BCL-xL/BAK complex is found in all cohorts before and 90 min following intraperitoneal cisplatin injection. The results shown are representative of the analysis of at least three mice per genotype.

aggregation of chromatin at the nuclear membrane were all noted in the $I G F B P 1^{-/-}$hepatocytes relative to the controls (Fig. 6C). Immunohistochemical analysis also revealed a greater degree of staining for active caspase-3 (p17) in the IGFBP1 $1^{-/-}$hepatocytes, relative to those in the wild-type $I G F B P 1^{+/+}$livers at $1 \mathrm{~h}$ (data not shown) and $3 \mathrm{~h}$ following intraperitoneal injection of cisplatin (Fig. 6H).

In the cisplatin-treated wild-type livers containing IGFBP1, there was no evidence of mitochondrial p53 accumulation or p53/BAK complexes (Fig. 6A,I,J). In contrast, p53 coimmunoprecipitated with BAK in the IGFBP $1^{-/-}$livers, both before and after cisplatin exposure (Fig. 6J). While there was no obvious increase in the relative abundance of mitochondrial p53 or the p53/BAK complex after cisplatin treatment, we attribute this to a rapid destruction in mitochondrial membrane integrity and perhaps mitochondrial fragmentation (Brooks et al. 2007), which precedes caspase activation and the more stable appearance of cleaved forms of caspase- 3 and PARP, as also illustrated in Figure 2.

\section{$\alpha$-Amanitin induces p53-mediated mitochondrial apoptosis in liver}

Genotoxic agents such as cisplatin (see Figs. 5, 6) and $\gamma$-irradiation (Reynolds et al. 2004) trigger a temporally related increase in the expression of IGFBP1. The functions of IGFBP1 reported here provide a reasonable explanation for the lack of p53 mitochondrial accumulation or apoptosis induction reported previously for livers of mice following exposure to $\gamma$-irradiation (Erster et al. 2004). In contrast to such DNA damaging agents, $\alpha$-amanitin has been shown to inhibit transcription and to elicit apoptosis in hepatocytes both in vitro and in vivo (Leist et al. 1994; Hentze et al. 2004; Wills et al. 2005; Zhao et al. 2006). This compound is the primary toxicological amatoxin in the "death cap" mushroom Amanita phalloides, and liver is one of the most sensitive organs to $\alpha$-amanitin poisoning (Wills et al. 2005; Zhao et al. 2006). However, little is known about the underlying molecular pathways involved. Therefore, we were interested in determining if $\alpha$-amanitin would induce p53 mitochondrial accumulation and concomitant apoptosis induction in mouse liver as it does in cultured cells.

For these analyses, we used both wild-type mice and the IGFBP1-deficient animals, to determine if they would differ in the extent of hepatic toxicity induced since, as anticipated, there was no up-regulation of IGFBP1 expression following $\alpha$-amanitin treatment (Fig. 7A). Histological examination of $\alpha$-amanitin-treated wild-type livers $(n=8)$ revealed multiple areas of focal hemorrhage and destruction of parenchymal architecture (Fig. 7B), which was comparable with that in the treated IGFBP1 $1^{-/-}$livers $(n=7)$ (Fig. 7B). In addition, the hepatic injury noted in both wild-type and IGFBP1-/livers was accompanied by widespread apoptosis, as indicated by TUNEL-positive and caspase-3 p17-positive staining (Fig. 7C; Supplementary Fig. S4G). Consistent with our in vitro and in vivo analyses (Figs. 2-6), apoptosis induction in the $\alpha$-amanitin-treated wild-type livers coincided with mitochondrial accumulation of p53 (Fig. 
Figure 7. Markedly attenuated $\alpha$-amanitin-mediated hepatic injury and apoptosis in $p 53^{-/-}$or $B A K^{-/-}$ livers. (A) Whole-cell extracts (WCE) were prepared from wild-type (WT) livers and examined by Western blot analyses for the proteins indicated, following a 90-min treatment of the animals with cisplatin (Cis) or $24 \mathrm{~h} \alpha$-amanitin ( $\alpha$-am). (B) H\&E staining of control wild-type (WT) liver, control IGFBP1-/$\left(B P 1^{-/-}\right)$liver, wild-type liver $24 \mathrm{~h}$ after $\alpha$-amanitin treatment, and $B P 1^{-/-}$liver $24 \mathrm{~h}$ after $\alpha$-amanitin treatment. Bars, $100 \mu \mathrm{m}$. (C) Apoptosis assayed in the indicated livers by TUNEL or anti-caspase-3 p17 staining. The brown staining indicates positive TUNEL or anti-caspase-3 p17 staining. Arrowheads in control $B P 1^{-/}$liver indicate positive TUNEL staining. Bars, $100 \mu \mathrm{m}$. (D) Western blot of proteins from mitochondrial (Mito) fractions prepared from control and $\alpha$-amanitin-treated wild-type livers. $(E)$ $\mathrm{H} \& \mathrm{E}$ staining of control $B A K^{-1-}$ liver, $B A K^{-/-}$liver $24 \mathrm{~h}$ after $\alpha$-amanitin treatment, and $\alpha$-amanitintreated $p 53^{-/-}$liver. Negligible parenchymal injury and focal hemorrhage were noted in the $\alpha$-amanitintreated $B A K^{-1-}$ or $p 53^{-/-}$livers relative to the corresponding wild-type or $B P 1^{-/-}$livers (shown in $B$ ). Bars, $100 \mu \mathrm{m}$. (F) Markedly reduced positive TUNEL or anti-caspase-3 p17 staining noted in $B A K^{-/-}$liver $24 \mathrm{~h}$ after $\alpha$-amanitin treatment. Bars, $100 \mu \mathrm{m} .(G)$ TUNEL or anti-caspase-3 p17 staining in $p 53^{-/-}$livers $24 \mathrm{~h}$ after $\alpha$-amanitin treatment. Note the generally intact parenchyma in either the $p 53^{-/-}(E)$ or $B A K^{-/-}(E)$ livers. Like the $\alpha$-amanitin-treated $B A K^{-/-}$livers $(F)$, trace amounts of positive TUNEL or anti-caspase-3 p17 staining were noted in $p 53^{-/-}$liver $24 \mathrm{~h}$ after $\alpha$-amanitin treatment, relative to the corresponding wild-type or $B P 1^{-/-}$livers $(C)$. Bars, $100 \mu \mathrm{m}$. $(H)$ Western blot of proteins from Mito fractions prepared from control wild-type, control $B A K^{-/-}$, $\alpha$-amanitin-treated wild-type, and $\alpha$-amanitin-treated $B A K^{-/-}$livers. The results shown are representative of the analysis of at least three mice per genotype.

7D). Additionally, mitochondrial accumulation of p53 correlated with proteolytic cleavage of PARP and caspase- 3 in the $\alpha$-amanitin-treated wild-type livers (Fig. $7 \mathrm{~A}, \mathrm{C})$, as noted previously in both primary MEFs and the HepG2 cells.

We extended these studies to test the in vivo requirement for p53 and its mitochondrial binding partner BAK in contributing to the amanitin-induced liver damage. For these analyses, we employed p53-null $(n=3)$ or BAKnull $(n=9)$ animals. Unlike the $\alpha$-amanitin-treated wildtype or IGFBP1 $1^{-/-}$cohorts (Fig. $7 \mathrm{~B}, \mathrm{C}$ ), there was a significant reduction in the amount of liver hemorrhage, parenchymal injury, and TUNEL-positive and caspase-3 p17-positive apoptotic cells in either the $\alpha$-amanitintreated p53-deficient or $\alpha$-amanitin-treated $B A K$-deficient animals (Fig. 7E-G; Supplementary Fig. S4G). Also, consistent with the results we obtained using primary $B A K$-null MEFs, the $B A K^{-/-}$livers exhibited no detectable accumulation of p53 at mitochondria (Fig. $7 \mathrm{H}$ ). Taken together, the absence of BAK (Fig. 7E,F) or the absence of p53 (Fig. 7E,G) provided protection from the $\alpha$-amanitin-induced liver damage. More significantly, these data strengthen the physiologic relevance of p53's direct apoptotic role at mitochondria, at least in these cell types, as well as the importance of BAK as a mediator of p53's mitochondrial functions.

\section{Discussion}

\section{A p53/IGFBP1 regulatory circuit and liver apoptosis}

In this work, we uncovered a previously unrecognized physiologic function of intracellular IGFBP1-as a BAKbinding regulator of apoptosis in hepatocytes. IGFBP1 is up-regulated in response to activation of the p53 tumor suppressor. In turn, the intracellular IGFBP1 protein impairs the induction of apoptosis, antagonizing the actions of p53 at mitochondria. Our studies indicate that the induced expression of IGFBP1 coordinates the transcription-dependent and transcription-independent activities of p53 and affects the stress response outcome in hepatocytes. In addition, as an antagonist of the interaction between p53 and BAK, the actions of IGFBP1 identify another aspect of p53 regulation, at the level of its extranuclear mitochondrial functions.

As a transcription factor, stress-activated p53 up-regulates the expression of a number of genes whose products act to promote apoptosis. On the other hand, p53 also induces factors, such as IGFBP1, that help to evade cell death (Oren 2003; Levine et al. 2006; Vousden and Lane 2007). Also illustrative of the latter activity is the finding that $\gamma$-irradiation of certain hematopoietic progenitor cells leads to the p53-induced up-regulation of the transcription factor SLUG. The SLUG protein then represses 
the p53-mediated transactivation of the proapoptotic gene puma, thereby antagonizing the induction of apoptosis (Wu et al. 2005). Other recent examples include TIGAR (Bensaad et al. 2006) and RhoE (Ongusaha et al. 2006), two p53-regulated factors that can provide protection against oxidative or genotoxic stress-mediated apoptosis, respectively. Normal tissues and cells exhibit a good deal of variability in terms of their sensitivity to p53-mediated apoptosis (Rubin and Casarett 1968; Gudkov and Komarova 2003; Ringshausen et al. 2006). Thus, it seems likely that diverse signaling mechanisms may have evolved to prevent, or delay for a time, the potentially lethal effects of p53, perhaps allowing time for repair of damage or resolution of metabolic distress.

Role of the p53 mitochondrial pathway in the cellular response to a transcription blockade

Current information indicates that the transcription-independent role of p53 likely potentiates, or cooperates with, its transcriptional regulatory activities to achieve apoptosis under many circumstances. In addition, however, it has long been recognized that inhibiting mRNA transcription acts as a trigger for the induction of p53mediated apoptosis in both normal and transformed cells. While a transcriptional blockage impedes p53's ability to induce the expression of critical proapoptotic genes as well as prosurvival factors, it results in the mitochondrial targeting of p53 and apoptosis induction (Figs. 2, 3, 7; Arima et al. 2005). Thus, through its direct apoptotic role at mitochondria, the p53 tumor suppressor retains the ability to eliminate cells that are genetically damaged or metabolically compromised even when the transcriptional machinery is impaired. In this regard, it is known that infection of mammalian cells with viral or bacterial pathogens can lead to a mRNA degradation or inhibition of protein synthesis that induces an apoptotic response. Among the mechanisms used by pathogens to evade such host defense mechanisms is the production of survival proteins that suppress BAK-mediated apoptosis (Cuconati et al. 2003; Wasilenko et al. 2005; Kvansakul et al. 2007; Shimazu et al. 2007). It will be of interest, therefore, to determine whether the p53 mitochondrial pathway also participates in cell death mediated by such protein synthesis inhibition.

\section{Prosurvival BAK-binding proteins and the response of hepatocytes to stress}

Approximately $80 \%$ of hepatic parenchyma is comprised of hepatocytes, which normally do not divide in healthy adults. However, the liver is somewhat unique in that it retains an ability to restore loss of mass following injury by compensatory proliferation of hepatocytes. The toxinor injury-mediated death of hepatocytes can trigger a reactive response in nonhepatocyte liver cells, often associated with inflammation and cytokine production to promote proliferation. Current models suggest that chronic or elevated hepatocyte apoptosis, resulting in compensatory proliferation in the presence of inflammatory cytokines and increased oxidative stress, may promote genetic and metabolic changes that predispose to tissue injury and dysplasia, conditions that constitute a risk factor for tumor development (Fausto 2000; Coleman 2003; Guicciardi and Gores 2005). Thus, in a tissue such as liver it may be beneficial for p53 to have an initially protective role in response to various forms of stress; induction of a prosurvival factor such as IGFBP1 would allow time for hepatocytes to repair or recover from low-level damage and escape apoptosis. However, if the damage persists or exceeds a critical threshold and IGFBP1 levels decrease, the hepatocytes would then be susceptible to cell death induction.

The identification of IGFBP1 as an inducible BAK regulator also raises the question of whether IGFBP1 works coordinately with, or is independent of, the various BCL2-related proteins in controlling hepatocyte apoptosis. Recent studies suggest that in healthy cells, the prodeath role of BAK can be held in check through sequestration, most likely in separate complexes, by prosurvival proteins such as BCL-xL and MCL1 (Cuconati et al. 2003; Leu et al. 2004; Willis et al. 2005; Shimazu et al. 2007; Willis et al. 2007). Currently, the relative proportion of BAK that normally is bound by particular prosurvival factors in different cells and tissues is not known; as recently noted, this question has been challenging to address, in part because buffer conditions can affect the interactions of certain BCL2 family proteins (Willis et al. 2005; Uren et al. 2007). However, the presence in a cell of multiple prosurvival guardians of BAK, whose abundance and activity are subject to diverse and complex mechanisms of regulation, suggests that there exist different pathways to BAK activation, and/or that multiple levels of restraint on BAK may protect against an accidental or undesirable induction of apoptosis. Such redundancy also would allow for a greater measure of control over mitochondrial integrity in response to different kinds and degrees of physiologic stress and exogenous insult.

It is well documented that an important determinant of whether or not a cell will undergo apoptosis is the relative abundance and availability of the various proapoptotic and anti-apoptotic members of the BCL2 protein family; they are subject to complex regulatory control, and some members of this family physically and/or functionally interact to either promote or inhibit the activation of BAK (Gelinas and White 2005; Adams and Cory 2007). The IGFBP1, BCL-xL, and MCL1 proteins all are expressed at low levels in the quiescent adult mouse liver (Tzung et al. 1997). Although MCL1 expression remains low or is lost following hepatic insults (Tzung et al. 1997), IGFBP1, which is not a BCL2 family protein, is one of the most highly induced liver factors following many forms of hepatic stress, including liver regeneration (Leu et al. 2001, 2003a; White et al. 2005). In addition, IGFBP1 induction precedes increases in BCL-xL levels in the liver following exogenous insults (Tzung et al. 1997; Fausto 2000; Leu et al. 2003b). Interestingly, enhanced BCL-xL expression following Fas mAb chal- 
lenge (Leu et al. 2003b) or the presence of a BCL-xL/BAK complex following cisplatin-mediated toxicity (Fig. 6J) is not sufficient to protect IGFBP1 $1^{-/-}$livers from apoptosis. Thus, the stressed-induced up-regulation of IGFBP1 may act within a defined window of time as a first line of defense to antagonize BAK activation in hepatocytes. Increases and decreases in the expression levels of IGFBP1 have been associated with a variety of liver diseases. For instance, a significant down-regulation of IGFBP1 has been noted in obese patients with nonalcoholic steatohepatitis (NASH), a disorder associated with increased apoptosis and mitochondrial dysfunction (Younossi et al. 2005). In contrast, elevated levels of IGFBP1 have been reported in patients with liver cirrhosis and/or hepatocellular carcinoma (Lee et al. 1997; Hwang et al. 2003), which often correlate with enhanced cellular proliferation and evasion of cell death (Guicciardi and Gores 2005). Consequently, stress signaling events that alter IGFBP1 expression and its interaction with BAK could have an important influence on the timing, or extent, of this protein's cytoprotective actions.

\section{The importance of $B A K$ for the p53 mitochondrial pathway of apoptosis}

Our analyses of genetic mouse models, together with in vitro analyses and cell culture experiments, provide additional support for the physiologic relevance of mitochondrial actions of $\mathrm{p} 53$, and the importance of its interactions with BAK, for promoting apoptosis. We found that when cells are BAK-deficient, or when p53's access to mitochondrial BAK is antagonized by the small molecule PFT- $\mu$ or by the formation of a complex between BAK and IGFBP1, then the induction of apoptosis is severely inhibited. In contrast, the loss of IGFBP1 sensitizes liver hepatocytes to spontaneous and stress-induced apoptosis, associated with p53 mitochondrial accumulation and BAK binding, as noted in the IGFBP1-1livers (Figs. 5-7), or in the $\alpha$-amanitin-treated wild-type livers (Fig. 7).

$\alpha$-Amanitin is the major amatoxin peptide found in the Amanita species of poison mushrooms. Liver is a primary site of amanitin toxicity, but little is known about the underlying molecular mechanisms involved. Moreover, there is no effective therapy for amanitin poisoning; it is often lethal and liver transplantation remains the primary treatment. Data obtained in this work on p53-null and $B A K$-null mice indicate that amanitininduced liver damage is greatly reduced in the absence of p53 mitochondrial accumulation. Thus, additional insight regarding the actions of IGFBP1, p53, and the mitochondrial pathway of apoptosis in hepatocytes could lead to new treatment strategies to reduce the pathologic effects of this mushroom toxin. Correspondingly, restoring critical aspects of p53 function represents a current target for the development of strategies and therapeutics in oncology. Progress in this area will benefit from a better understanding of the potentially opposing functions of p53 in promoting cell survival or apoptosis, and a characterization of the various cell-specific signaling pathways that modulate the p53 response.

\section{Materials and methods}

Mice

The IGFBP1 knockout mouse was generated as reported previously (Leu et al. 2003a,b) and backcrossed to C57BL/6 (The Jackson Laboratory) for 12 generations. The $p 53^{-/-}$and $B A K^{-1-}$ animals in the C57BL/6 background were purchased from The Jackson Laboratory. All experiments with mice conformed to the guidelines of The Institutional Animal Care and Use Committee of the University of Pennsylvania School of Medicine, which approved all animal work according to federal and institutional policies and regulations. For Figures 5 and 6, we used livers isolated from IGFBP1 $1^{+/+}$and $I G F B P 1^{-/-}$male (only) mice, 10-12 wk of age in the C57BL/6 background. The mice were either deprived of food (but not water) for $24 \mathrm{~h}$ or injected intraperitoneally for 90 min with EGF (1 $\mu \mathrm{g}$ per gram of body weight; Roche Applied Science), cisplatin (50 $\mu \mathrm{g}$ per gram of body weight; EMD Biosciences, Inc.), or Fas mAb (0.25 $\mu$ g per gram of body weight; BD Biosciences-Pharmingen). For Figure 6, we also isolated livers from $I G F B P 1^{+/+}$and $I G F B P 1^{-/-}$male (only) mice, 10-12 wk of age in the C57BL/6 background, before and after intraperitoneal treatment with cisplatin (50 $\mu \mathrm{g}$ per gram of body weight; EMD Biosciences, Inc.). For Figure 7, we isolated livers from wild-type, IGFBP1 $1^{-/-}, B A K^{-/-}$, and $p 53^{-/-}$ male mice, 4-5 wk of age in the C57BL/ 6 background, following intraperitoneal injection with $\alpha$-amanitin ( $5 \mu \mathrm{g}$ per gram of body weight; EMD Biosciences, Inc.). We chose to use animals between 4 and 5 wk of age for the $\alpha$-amanitin study, in part because the p53-null animals have a relatively short life span and a natural propensity to develop tumors by $\sim 9$ wk of age. All livers were analyzed histologically by staining sections with hematoxylin and eosin (H\&E).

\section{Cell culture}

Primary wild-type and $B A K^{-1-}$ MEFs were harvested from 13.5d-old embryos and used at passage 3-5. U2OS, MCF7, and HepG2 cell lines were cultured in DMEM as described (Dumont et al. 2003; Leu et al. 2004). The HepG2 cells were maintained at $40 \%-50 \%$ confluency, because IGFBP1 is a density-regulated factor. The U2OS and MCF7 cells were transfected with fulllength human IGFBP1-encoding cDNA using Fugene 6 (Roche Applied Science). The stable clones were selected as described (Dumont et al. 2003). Nutlin-3 was purchased from Cayman Chemical Company. Cisplatin, doxorubicin, PFT- $\mu$, and $\alpha$-amanitin were purchased from EMD Biosciences, Inc.

\section{Identification of BAK-interacting proteins}

HepG2 cells, untreated or treated with $10 \mu \mathrm{M}$ Nutlin-3, typically for $24 \mathrm{~h}$, were lysed in $0.5 \%$ CHAPS IP-Buffer $(50 \mathrm{mM}$ Tris- $\mathrm{HCl}$ at $\mathrm{pH} 7.5,150 \mathrm{mM} \mathrm{NaCl}, 5 \mathrm{mM}$ EDTA, $250 \mathrm{mM}$ sucrose, $0.5 \%$ CHAPS) supplemented with protease inhibitors. The homogenates were spun at $14,000 \mathrm{rpm}$ for $15 \mathrm{~min}$ at $4^{\circ} \mathrm{C}$, and 10-30 mg of supernatants (whole-cell extracts) were incubated with anti-BAK NT antibody overnight at $4^{\circ} \mathrm{C}$ on a rocker. The BAK-containing immunocomplexes were captured by adding the recombinant Protein G Agarose (Invitrogen). The immunocomplex-agarose beads were washed three times using $0.5 \%$ CHAPS IP-Buffer, and the associated proteins were resolved by SDS-PAGE in a $4 \%-20 \%$ gradient gel /Cambrex Bio Science 
Rockland, Inc.) and visualized by Coomassie staining (Bio-Rad Laboratories, Inc.). The Coomassie-stained band of $\sim 30 \mathrm{kDa}$ was excised from the gel and subjected to trypsin digestion, and the resulting peptides were analyzed by liquid chromatographytandem mass spectrometry at the Genomics Institute and Abramson Cancer Center Proteomics Core Facility, University of Pennsylvania School of Medicine.

\section{Immunoblotting, cell fractionation, BAK oligomerization, immunoprecipitation, and in vitro binding}

HepG2 culture media samples containing secreted IGFBP1 protein were harvested and centrifuged at $14,000 \mathrm{rpm}$ for $5 \mathrm{~min}$ to remove cellular debris. The HepG2 cells were washed twice with $1 \times$ Dulbecco's Phosphate-Buffered Saline (D-PBS without calcium or magnesium; Invitrogen Corporation) and lysed either in RIPA Buffer or in $0.5 \%-2 \%$ CHAPS IP-Buffer. Protein concentration of cellular and medium extracts was determined using the Bradford Reagent (Rio-Rad Laboratories). Immunoblotting (Western blotting) of cultured cell extracts was performed as described (Dumont et al. 2003; Leu et al. 2004). Cell fractionations and BAK oligomerization assays were performed as published (Dumont et al. 2003; Leu et al. 2004). Five milligrams to $10 \mathrm{mg}$ of whole-cell extracts prepared in $0.5 \%-2 \%$ CHAPS IP-Buffer were used for coimmunoprecipitation assays. The in vitro binding experiments were performed as described (Leu et al. 2004) in 0.5\% CHAPS IVT-Buffer (50 mM Tris- $\mathrm{HCl}$ at $\mathrm{pH} 7.5,150 \mathrm{mM} \mathrm{NaCl}, 5 \mathrm{mM}$ EDTA, 0.5\% CHAPS). For the in vitro binding studies employing isolated mitochondria from HepG2 cells before and after Nutlin-3 treatment, $75 \mu \mathrm{g}$ of mitochondria were mixed with $50 \mathrm{ng}$ of purified p53 recombinant protein in Fractionation Buffer B (Leu et al. 2004) for 30 min at $30^{\circ} \mathrm{C}$. Following incubation, the preparations were spun at $7000 \mathrm{~g}$ for $10 \mathrm{~min}$ at $4^{\circ} \mathrm{C}$, and the mitochondria-protein complexes were washed with Fractionation Buffer B. The postwashed mitochondria-protein complexes were resuspended in $2 \%$ CHAPS-IP Buffer for coimmunoprecipitation assays. The following primary antibodies were used in this work: anti-BAK, anti-caspase-3, anti-cleaved-caspase-3, anti-caspase-8 (human specific), anti-caspase-8 (mouse specific), anti-PUMA, anticleaved PARP (mouse specific), and anti-BCL-xL (Cell Signaling Technology, Inc.); anti-p53 (AB-6), anti-MDM2, anti-p21, antiHSP60, anti-PARP, and anti-PUMA (EMD Biosciences, Inc.); anti-p53 CM5 (mouse specific, Vector Laboratories); anti-p53 (NCL-p53-505, Vision Biosystems, Inc.); anti-IGFBP1 (sc-6000) and anti-GRP75 (Santa Cruz Biotechnology, Inc.); anti-IGFBP1 (human specific) and anti-BAK NT (Upstate Biotechnology USA, Inc.); anti-MCL1 and anti-BCL-xL (BD BiosciencesPharmingen); and anti-BID and anti-active caspase-3 (R\&D Systems, Inc.). The peroxidase-conjugated secondary antibodies (i.e., donkey anti-rabbit, donkey anti-mouse, and donkey antigoat) were from Jackson ImmunoResearch Laboratories, Inc.

\section{Immunofluorescence and immunohistochemical analyses}

The immunohistochemical analysis using anti-active caspase-3 (R\&D Systems, Inc.) was performed as described (Leu et al. 2003b). The immunofluorescence microscopy was performed as described (Dumont et al. 2003). The TUNEL staining was done using ApopTag Peroxidase In Situ Apoptosis Detection Kit (S7100, Chemicon International, Inc.). Detailed protocols for both TUNEL and active caspase-3 immunohistochemical staining can be obtained by contacting University of Pennsylvania Department of Medicine, Gastroenterology Division Center for Molecular Studies of Digestive and Liver Diseases, Morphology Core. Determination of apoptosis-positive cells by staining for
Annexin $\mathrm{V}$ was performed as described previously (Dumont et al. 2003). The results presented are the mean Annexin V-positive staining \pm standard deviation from three independent analyses. For senescence-activated $\beta$-galactosidase staining, we used Senescence Cells Histochemical Staining Kit (Sigma-Aldrich) following the manufacturer's instructions.

\section{Plasmid constructs and site-directed mutagenesis}

Plasmids BAK, BAX, MCL1, and BCL-xL have been described (Leu et al. 2004). The full-length human pcDNA-BAD construct was purchased from Sciencereagents. The pcDNA-IGFBP1 construct was obtained by PCR amplification using a pCR-IGFBP1 construct (kindly provided by Douglas Yee, University of Minnesota Cancer Center, Minneapolis, MN).

\section{Acknowledgments}

We thank K. Olthoff for providing IGFBP1-/- breeders, D. Yee for the pCR-IGFBP1 construct, and G. Swain and the Penn Morphology Core, Center for Molecular Studies in Digestive and Liver Disease, for advice and help with tissue staining and photography. We are grateful to S. Liebhaber and M. Murphy for valuable discussions and critical review of the manuscript. Portions of this work were supported by grants from the NIH (CA089240, CA118761) and funds provided by the University of Pennsylvania School of Medicine/GSK ADDI Collaboration, the University of Pennsylvania Abramson Cancer Center, and the Center for Molecular Studies in Digestive and Liver Disease (P30-DK050306). J.L. was supported by NIH F32CA112715 and K01DK078025.

\section{References}

Adams, J. and Cory, S. 2007. The Bcl-2 apoptotic switch in cancer development and therapy. Oncogene 26: 324-337.

Amundson, S., Myers, T., Scudiero, D., Kitada, S., Reed, J., and Fornace Jr., A. 2000. An informatics approach identifying markers of chemosensitivity in human cancer cell lines. Cancer Res. 60: 6101-6110.

Arima, Y., Nitta, M., Kuninaka, S., Zhang, D., Fujiwara, T., Taya, Y., Nakao, M., and Saya, H. 2005. Transcriptional blockade induces p53-dependent apoptosis associated with translocation of p53 to mitochondria. J. Biol. Chem. 280: 19166-19176.

Bensaad, K., Tsuruta, A., Selak, M., Vidal, M., Nakano, K., Bartrons, R., Gottlieb, E., and Vousden, K. 2006. TIGAR, a p53inducible regulator of glycolysis and apoptosis. Cell 126: 107-120.

Brooks, C., Wei, Q., Feng, L., Dong, G., Tao, Y., Mei, L., Xie, Z., and Dong, Z. 2007. Bak regulates mitochondrial morphology and pathology during apoptosis by interacting with mitofusins. Proc. Nat1. Acad. Sci. 104: 11649-11654.

Caelles, C., Helmberg, A., and Karin, M. 1994. p53-dependent apoptosis in the absence of transcriptional activation of $\mathrm{p} 53$ target genes. Nature 370: 220-223.

Chen, X., Ko, L.J., and Prives, C. 1996. p53 levels, functional domains, and DNA damage determine the extent of the apoptotic response of tumor cells. Genes \& Dev. 10: 2438 2451.

Chipuk, J., Maurer, U., Green, D., and Schuler, M. 2003. Pharmacologic activation of p53 elicits Bax-dependent apoptosis in the absence of transcription. Cancer Cell 4: 371-381.

Chipuk, J., Kuwana, T., Bouchier-Hayes, L., Droin, N., Newmeyer, D., Schuler, M., and Green, D. 2004. Direct activa- 
tion of Bax by p53 mediates mitochondrial membrane permeabilization and apoptosis. Science 303: 1010-1014.

Chipuk, J., Bouchier-Hayes, L., Kuwana, T., Newmeyer, D., and Green, D. 2005. PUMA couples the nuclear and cytoplasmic proapoptotic function of p53. Science 309: 1732-1735.

Cohen, P. 2006. Insulin-like growth factor binding protein-3: Insulin-like growth factor independence comes of age. Endocrinology 147: 2109-2111.

Coleman, W. 2003. Mechanisms of human hepatocarcinogenesis. Curr. Mol. Med. 3: 573-588.

Cuconati, A., Mukherjee, C., Perez, D., and White, E. 2003. DNA damage response and MCL-1 destruction initiate apoptosis in adenovirus-infected cells. Genes \& Dev. 17: 29222932.

Cullinane, C., Mazur, S., Essigmann, J., Phillips, D., and Bohr, V. 1999. Inhibition of RNA polymerase II transcription in human cell extracts by cisplatin DNA damage. Biochemistry 38: 6204-6212.

Duan, C. and Xu, Q. 2005. Roles of insulin-like growth factor (IGF) binding proteins in regulating IGF actions. Gen. Comp. Endocrinol. 142: 44-52.

Dumont, P., Leu, J., Della Pietra III, A., George, D., and Murphy, M. 2003. The codon 72 polymorphic variants of $p 53$ have markedly different apoptotic potential. Nat. Genet. 33: 357365.

Erster, S., Mihara, M., Kim, R., Petrenko, O., and Moll, U. 2004. In vivo mitochondrial p53 translocation triggers a rapid first wave of cell death in response to DNA damage that can precede p53 target gene activation. Mol. Cell. Biol. 24: 67286741.

Fausto, N. 2000. Liver regeneration. J. Hepatol. 32: 19-31.

Firth, S. and Baxter, R. 2002. Cellular actions of the insulin-like growth factor binding proteins. Endocr. Rev. 23: 824-854.

Gelinas, C. and White, E. 2005. BH3-only proteins in control: Specificity regulates MCL-1 and BAK-mediated apoptosis. Genes \& Dev. 19: 1263-1268.

Griffiths, G., Dubrez, L., Morgan, C., Jones, N., Whitehouse, J., Corfe, B., Dive, C., and Hickman, J. 1999. Cell damage-induced conformational changes of the pro-apoptotic protein Bak in vivo precede the onset of apoptosis. J. Cell Biol. 144: 903-914.

Gudkov, A. and Komarova, E. 2003. The role of p53 in determining sensitivity to radiotherapy. Nat. Rev. Cancer 3: 117129.

Guicciardi, M. and Gores, G. 2005. Apoptosis: A mechanism of acute and chronic liver injury. Gut 54: 1024-1033.

Haupt, Y., Rowan, S., Shaulian, E., Vousden, K., and Oren, M. 1995. Induction of apoptosis in HeLa cells by trans-activation-deficient p53. Genes \& Dev. 9: 2170-2183.

Hentze, H., Latta, M., Kunstle, G., Dhakshinamoorthy, S., Ng, P., Porter, A., and Wendel, A. 2004. Topoisomerase inhibitor camptothecin sensitizes mouse hepatocytes in vitro and in vivo to TNF-mediated apoptosis. Hepatology 39: 1311-1320.

Hwang, D., Huang, S., Lan, W., and Lee, P. 2003. Elevated insulin, proinsulin and insulin-like growth factor-binding protein-1 in liver disease. Growth Horm. IGF Res. 13: 316-321.

Jeffers, J., Parganas, E., Lee, Y., Yang, C., Wang, J., Brennan, J., MacLean, K., Han, J., Chittenden, T., Ihle, J., et al. 2003. Puma is an essential mediator of p53-dependent and -independent apoptotic pathways. Cancer Cell 4: 321-328.

Jiang, P., Du, W., Heese, K., and Wu, M. 2006. The Bad guy cooperates with good cop p53: Bad is transcriptionally upregulated by $\mathrm{p} 53$ and forms a Bad/p53 complex at the mitochondria to induce apoptosis. Mol. Cell. Biol. 26: 9071-9082.

Jung, Y. and Lippard, S. 2006. RNA polymerase II blockage by cisplatin-damaged DNA. Stability and polyubiquitylation of stalled polymerase. J. Biol. Chem. 281: 1361-1370.

Kvansakul, M., van Delft, M., Lee, E., Gulbis, J., Fairlie, W. Huang, D., and Colman, P. 2007. A structural viral mimic of prosurvival Bcl-2: A pivotal role for sequestering proapoptotic Bax and Bak. Mol. Cell 25: 933-942.

Laptenko, O. and Prives, C. 2006. Transcriptional regulation by p53: One protein, many possibilities. Cell Death Differ. 13: 951-961.

Lee, P., Giudice, L., Conover, C., and Powell, D. 1997. Insulinlike growth factor binding protein-1: Recent findings and new directions. Proc. Soc. Exp. Biol. Med. 216: 319-357.

Leist, M., Gantner, F., Bohlinger, I., Germann, P., Tiegs, G., and Wendel, A. 1994. Murine hepatocyte apoptosis induced in vitro and in vivo by TNF- $\alpha$ requires transcriptional arrest. J. Immunol. 153: 1778-1788.

Leu, J., Crissey, M., Leu, J., Ciliberto, G., and Taub, R. 2001. Interleukin-6-induced STAT3 and AP-1 amplify hepatocyte nuclear factor 1-mediated transactivation of hepatic genes, an adaptive response to liver injury. Mol. Cell. Biol. 21: 414424

Leu, J., Crissey, M., Craig, L., and Taub, R. 2003a. Impaired hepatocyte DNA synthetic response posthepatectomy in insulin-like growth factor binding protein 1-deficient mice with defects in C/EBP $\beta$ and mitogen-activated protein kinase/extracellular signal-regulated kinase regulation. Mol. Cell. Biol. 23: 1251-1259.

Leu, J., Crissey, M., and Taub, R. 2003b. Massive hepatic apoptosis associated with TGF- $\beta 1$ activation after Fas ligand treatment of IGF binding protein-1-deficient mice. J. Clin. Invest. 111: 129-139.

Leu, J., Dumont, P., Hafey, M., Murphy, M., and George, D. 2004. Mitochondrial p53 activates Bak and causes disruption of a Bak-Mcll complex. Nat. Cell Biol. 6: 443-450.

Levine, A., Hu, W., and Feng, Z. 2006. The P53 pathway: What questions remain to be explored? Cell Death Differ. 13: 1027-1036.

Ljungman, M., Zhang, F., Chen, F., Rainbow, A., and McKay, B. 1999. Inhibition of RNA polymerase II as a trigger for the p53 response. Oncogene 18: 583-592.

Lomonosova, E., Subramanian, T., and Chinnadurai, G. 2005. Mitochondrial localization of p53 during adenovirus infection and regulation of its activity by E1B-19K. Oncogene 24: 6796-6808.

Lu, S. and Archer, M. 2003. Insulin-like growth factor binding protein-1 over-expression in transgenic mice inhibits hepatic preneoplasia. Mol. Carcinog. 36: 142-146.

Marchand, A., Tomkiewicz, C., Magne, L., Barouki, R., and Garlatti, M. 2006. Endoplasmic reticulum stress induction of insulin-like growth factor-binding protein-1 involves ATF4. J. Biol. Chem. 281: 19124-19133.

Marchenko, N., Zaika, A., and Moll, U. 2000. Death signalinduced localization of p53 protein to mitochondria: A potential role in apoptotic signaling. J. Biol. Chem. 275: 1620216212 .

Mihara, M., Erster, S., Zaika, A., Petrenko, O., Chittenden, T., Pancoska, P., and Moll, U. 2003. p53 has a direct apoptogenic role at the mitochondria. Mol. Cell 11: 577-590.

Moll, U., Marchenko, N., and Zhang, X. 2006. p53 and Nur77/ TR3-Transcription factors that directly target mitochondria for cell death induction. Oncogene 25: 4725-4743.

Muller, M., Strand, S., Hug, H., Heinemann, E., Walczak, H., Hofmann, W., Stremmel, W., Krammer, P., and Galle, P. 1997. Drug-induced apoptosis in hepatoma cells is mediated by the CD95 (APO-1/Fas) receptor/ligand system and involves activation of wild-type p53. J. Clin. Invest. 99: 403413 
Nijhawan, D., Fang, M., Traer, E., Zhong, Q., Gao, W., Du, F., and Wang, X. 2003. Elimination of Mcl-1 is required for the initiation of apoptosis following ultraviolet irradiation. Genes \& Dev. 17: 1475-1486.

Ongusaha, P., Kim, H., Boswell, S., Ridley, A., Der, C., Dotto, G., Kim, Y., Aaronson, S., and Lee, S. 2006. RhoE is a prosurvival p53 target gene that inhibits ROCK I-mediated apoptosis in response to genotoxic stress. Curr. Biol. 16: 24662472.

Oren, M. 2003. Decision making by p53: Life, death and cancer. Cell Death Differ. 10: 431-442.

Pietsch, E., Leu, J., Dumont, P., George, D., and Murphy, M. 2007. The tetramerization domain of p53 is required for efficient BAK oligomerization. Cancer Biol. Ther. (in press). October

Qin, L. and $\mathrm{Ng}$, I. 2002. Induction of apoptosis by cisplatin and its effect on cell cycle-related proteins and cell cycle changes in hepatoma cells. Cancer Lett. 175: 27-38.

Reynolds, R., Witherspoon, S., and Fox, T. 2004. The infant mouse as a in vivo model for the detection and study of DNA damage-induced changes in the liver. Mol. Carcinog. 40: 6272.

Ringshausen, I., O'Shea, C., Finch, A., Swigart, L., and Evan, G. 2006. Mdm2 is critically and continuously required to suppress lethal p53 activity in vivo. Cancer Cell 10: 501-514.

Rubin, P. and Casarett, G. 1968. Clinical radiation pathology as applied to curative radiotherapy. Cancer 22: 767-778.

Scharf, J., Dombrowski, F., Novosyadlyy, R., Eisenbach, C., Demori, I., Kubler, B., and Braulke, T. 2004. Insulin-like growth factor (IGF)-binding protein-1 is highly induced during acute carbon tetrachloride liver injury and potentiates the IGF-Istimulated activation of rat hepatic stellate cells. Endocrinology 145: 3463-3472.

Shimazu, T., Degenhardt, K., Nur-E-Kamal, A., Zhang, J., Yoshida, T., Zhang, Y., Mathew, R., White, E., and Inouye, M. 2007. NBK/BIK antagonizes MCL-1 and BCL-XL and activates BAK-mediated apoptosis in response to protein synthesis inhibition. Genes \& Dev. 21: 929-941.

Sjögren, K., Liu, J., Blad, K., Skrtic, S., Vidal, O., Wallenius, V., LeRoith, D., Törnell, J., Isaksson, O., Jansson, J., et al. 1999. Liver-derived insulin-like growth factor I (IGF-I) is the principal source of IGF-I in blood but is not required for postnatal body growth in mice. Proc. Natl. Acad. Sci. 96: 7088-7092.

Skrtic, S., Wallenius, K., Sjogren, K., Isaksson, O., Ohlsson, C., and Jansson, J. 2001. Possible roles of insulin-like growth factor in regulation of physiological and pathophysiological liver growth. Horm. Res. 55 (Suppl. 1): 1-6.

Sot, B., Freund, S., Fersht, A. 2007. Comparative biophysical characterization of p53 with the pro-apoptotic bak and the anti-apoptotic BCL-X $\mathrm{X}_{\mathrm{L}}$. J. Biol. Chem. 282: 29193-29200.

Speidel, D., Helmbold, H., and Deppert, W. 2006. Dissection of transcriptional and non-transcriptional p53 activities in the response to genotoxic stress. Oncogene 25: 940-953.

Strom, E., Sathe, S., Komarov, P., Chernova, O.B., Pavlovska, I., Shyshynova, I., Bosykh, D., Burdelya, L., Macklis, R., Skaliter, R., et al. 2006. Small-molecule inhibitor of p53 binding to mitochondria protects mice from $\gamma$ radiation. Nat. Chem. Biol 2: 474-479.

Sundararajan, R., Cuconati, A., Nelson, D., and White, E. 2001. Tumor necrosis factor- $\alpha$ induces Bax-Bak interaction and apoptosis, which is inhibited by adenovirus E1B 19K. J. Biol. Chem. 276: 45120-45127.

Tzung, S., Fausto, N., and Hockenbery, D. 1997. Expression of Bcl-2 family during liver regeneration and identification of $\mathrm{Bcl}-\mathrm{x}$ as a delayed early response gene. Am. I. Pathol. 150: 1985-1995.
Uren, R., Dewson, G., Chen, L., Coyne, S., Huang, D., Adams, J., and Kluck, R. 2007. Mitochondrial permeabilization relies on $\mathrm{BH} 3$ ligands engaging multiple prosurvival Bcl-2 relatives, not Bak. J. Cell Biol. 177: 277-287.

Vassilev, L.T., Vu, B.T., Graves, B., Carvajal, D., Podlaski, F., Filipovic, Z., Kong, N., Kammlott, U., Lukacs, C., Klein, C., et al. 2004. In vivo activation of the p53 pathway by smallmolecule antagonists of MDM2. Science 303: 844-848.

Villunger, A., Michalak, E., Coultas, L., Mullauer, F., Bock, G., Ausserlechner, M., Adams, J., and Strasser, A. 2003. p53- and drug-induced apoptotic responses mediated by BH3-only proteins puma and noxa. Science 302: 1036-1038.

Vousden, K. and Lane, D.P. 2007. p53 in health and disease. Nat. Rev. Mol. Cell Biol. 8: 275-283.

Wasilenko, S., Banadyga, L., Bond, D., and Barry, M. 2005. The vaccinia virus F1L protein interacts with the proapoptotic protein Bak and inhibits Bak activation. J. Virol. 79: 1403114043.

Wei, M., Lindsten, T., Mootha, V., Weiler, S., Gross, A., Ashiya, M., Thompson, C., and Korsmeyer, S. 2000. tBID, a membrane-targeted death ligand, oligomerizes BAK to release cytochrome c. Genes \& Dev. 14: 2060-2071.

White, P., Brestelli, J.E., Kaestner, K., and Greenbaum, L. 2005. Identification of transcriptional networks during liver regeneration. J. Biol. Chem. 280: 3715-3722.

Willis, S., Chen, L., Dewson, G., Wei, A., Naik, E., Fletcher, J., Adams, J., and Huang, D. 2005. Proapoptotic Bak is sequestered by Mcl-1 and $\mathrm{Bcl}-\mathrm{x}_{\mathrm{L}}$, but not Bcl-2, until displaced by BH3-only proteins. Genes \& Dev. 19: 1294-1305.

Willis, S., Fletcher, J., Kaufmann, T., van Delft, M., Chen, L., Czabotar, P., Ierino, H., Lee, E., Fairlie, W., Bouillet, P., et al. 2007. Apoptosis initiated when $\mathrm{BH} 3$ ligands engage multiple Bcl-2 homologs, not Bax or Bak. Science 315: 856-859.

Wills, B., Haller, N., Peter, D., and White, L. 2005. Use of amifostine, a novel cytoprotective, in $\alpha$-amanitin poisoning. Clin. Toxicol. (Phila) 43: 261-267.

Wu, W., Heinrichs, S., Xu, D., Garrison, S., Zambetti, G., Adams, J., and Look, A. 2005. Slug antagonizes p53-mediated apoptosis of hematopoietic progenitors by repressing puma. Cell 123: 641-653.

Xue, W., Zender, L., Miething, C., Dickins, R., Hernando, E., Krizhanovsky, V., Cordon-Cardo, C., and Lowe, S. 2007. Senescence and tumour clearance is triggered by p53 restoration in murine liver carcinomas. Nature 445: 656-660.

Younossi, Z., Gorreta, F., Ong, J., Schlauch, K., Giacco, L., Elariny, H., Van Meter, A., Younoszai, A., Goodman, Z., Baranova, A., et al. 2005. Hepatic gene expression in patients with obesity-related non-alcoholic steatohepatitis. Liver Int. 25: 760-771.

Zhao, J., Cao, M., Zhang, J., Sun, Q., Chen, Q., and Yang, Z. 2006. Pathological effects of the mushroom toxin $\alpha$-amanitin on BALB/c mice. Peptides 27: 3047-3052. 


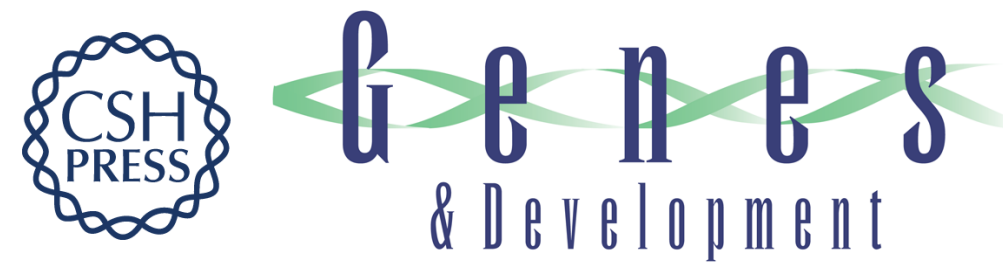

\title{
Hepatic IGFBP1 is a prosurvival factor that binds to BAK, protects the liver from apoptosis, and antagonizes the proapoptotic actions of p53 at mitochondria
}

\author{
J. I-Ju Leu and Donna L. George
}

Genes Dev. 2007, 21:

Access the most recent version at doi:10.1101/gad.1567107

\section{Supplemental http://genesdev.cshlp.org/content/suppl/2007/11/15/21.23.3095.DC1 \\ Material}

Related Content Protecting the Liver from Death

Nancy R. Gough

Sci. STKE December , 2007 2007: tw447

References This article cites 76 articles, 32 of which can be accessed free at:

http://genesdev.cshlp.org/content/21/23/3095.full.html\#ref-list-1

Articles cited in:

http://genesdev.cshlp.org/content/21/23/3095.full.html\#related-urls

\section{License}

Email Alerting

Service

Receive free email alerts when new articles cite this article - sign up in the box at the top right corner of the article or click here.

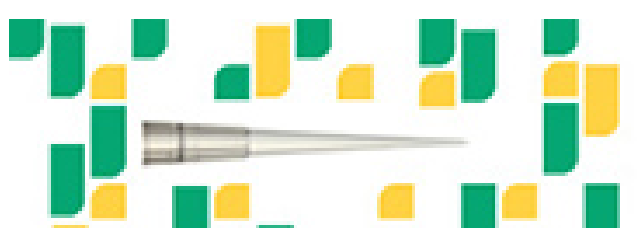

Focused on your science. 